\title{
Recombinant club cell protein 16 (CC16) ameliorates cigarette smoke-induced lung inflammation in a murine disease model of COPD
}

\author{
MIN PANG ${ }^{1}$, HONG-YAN LIU ${ }^{2}$, TING LI $^{1}$, DAN WANG ${ }^{1}$, XIAO-YUN HU ${ }^{1}$, \\ XIN-RI ZHANG ${ }^{1}$, BAO-FENG YU ${ }^{2}$, RUI GUO ${ }^{2}$ and HAI-LONG WANG ${ }^{2}$ \\ ${ }^{1}$ Department of Respiratory Medicine, The First Hospital; ${ }^{2}$ School of Basic Medicine, \\ Shanxi Medical University, Taiyuan, Shanxi 030001, P.R. China
}

Received February 2, 2018; Accepted June 21, 2018

DOI: $10.3892 / \mathrm{mmr} .2018 .9216$

\begin{abstract}
Club cell protein (CC16) is expressed primarily by club cells possesses anti-inflammatory properties and is located in the bronchiolar epithelium. Previous studies have demonstrated that CC16 deficiency is associated with the progression of chronic obstructive pulmonary disease (COPD). In the present study, the therapeutic effects of recombinant rat $\mathrm{CC} 16$ protein in mice with COPD were examined and the underlying mechanisms investigated. A total of 30 adult male C57/BL6 mice were randomly divided into three groups (10 mice/group). A mouse COPD model was generated by exposing 20 mice to cigarette smoke (CS) for 24 weeks. A total of 10 mice were treated intranasally with $\mathrm{rCC} 16(2.5 \mu \mathrm{g} / \mathrm{g}$ body weight) and control mice were exposed to normal room air. Results indicated that $\mathrm{rCC} 16$ treatment ameliorated pathological damage in the lungs and reduced the production of tumor necrosis factor (TNF)- $\alpha$, interleukin (IL)-6 and IL-8, which were induced by $\mathrm{CS}$ exposure. After rCC16 administration, endogenous CC16 was upregulated and the body weight of COPD mice was increased, whereas the opposite was observed in CS-exposed mice. Additionally, rCC16 treatment inhibited the DNA binding of NF- $\mathrm{BB} / \mathrm{p} 65$ in lung tissues and reduced nuclear translocation of $\mathrm{NF}-\kappa \mathrm{B} / \mathrm{p} 65$ in $\mathrm{BALF}$ and epithelial cells. Moreover, $\mathrm{rCC} 16$ treatment lead to a decrease in the total number of BALF cells, including macrophages,
\end{abstract}

Correspondence to: Professor Min Pang, Department of Respiratory Medicine, The First Hospital, Shanxi Medical University, 85 Jiefang South Road, Taiyuan, Shanxi 030001, P.R. China

E-mail: pangmin2009@126.com

Professor Hai-Long Wang, School of Basic Medicine, Shanxi Medical University, 56 Xinjian South Road, Taiyuan, Shanxi 030001, P.R. China

E-mail: longwty@163.com

Key words: recombinant rat $\mathrm{CC16}$, cigarette smoke, chronic obstructive pulmonary disease, pro-inflammatory cytokines, $\mathrm{NF}-\kappa \mathrm{B}$, intranasal administration which was elevated in COPD mice. In conclusion, the present results demonstrate that $\mathrm{rCC} 16$ has therapeutic effects on COPD by downregulating pro-inflammatory factors via the $\mathrm{NF}-\kappa \mathrm{B}$ pathway.

\section{Introduction}

Chronic obstructive pulmonary disease (COPD), a disabling and life-threatening disease, is associated with chronic inflammatory responses. By 2020, COPD is predicted to be the third leading cause of morbidity and mortality in the world $(1,2)$. Long-term exposure to cigarette smoke (CS) is a major risk factor for COPD and accounts for 80 90\% of COPD cases (3). CS exposure results in severe lung inflammation characterized by influx of inflammatory cells and secretion of cytokines in susceptible individuals (4). One type of these inflammatory cells are macrophages which play a crucial role in the progression of COPD as they secrete pro-inflammatory cytokines such as TNF- $\alpha$, IL-1 and IL-8 $(5,6)$. Although the mechanisms for the pathogenesis of COPD remain elusive, it is clear that CS-induced airway inflammatory response contributes to COPD. At present, standard COPD treatment includes inhaled corticosteroids in combination with long-acting $\beta 2$-agonists. However, these treatments are often ineffective due to reduced responsiveness to corticosteroids $(7,8)$. Therefore, new therapeutic strategies targeted to airway inflammatory response need to be devised.

The nuclear factor $-\kappa \mathrm{B}(\mathrm{NF}-\kappa \mathrm{B})$ transcription factor exists mainly as a heterodimer contained subunits of the Rel family p50 and p65 and is trapped in the cytoplasm of unstimulated cells. The inhibitor proteins of NF- $\kappa \mathrm{B}(\mathrm{I} \kappa \mathrm{B})$ masks the nuclear localization sequence which is contained in the Rel homology domain and retain $N F-\kappa B$ in the cytoplasm (9). When stimilated, the $\mathrm{I} \kappa \mathrm{B}$ kinase (IKK) complex is activated and triggers phosphorylation and degradation of $\mathrm{I} \kappa \mathrm{B} \alpha(10)$. The resulting free NF- $\kappa \mathrm{B}$ is translocated to the nucleus and induces the transcription of pro-inflammatory mediators including cytokines in macrophages in COPD $(5,6)$. Increased nuclear localization of p65 was observed in sputum macrophages and in bronchial biopsies of COPD patients $(11,12)$. Additionally, the increased $\mathrm{NF}-\kappa \mathrm{B}$ levels in serum were found in COPD patients compared 
to health controls (13). More and more studies showed that the $\mathrm{NF}-\kappa \mathrm{B}$ pathway has been implicated in COPD and indicated that modulating $\mathrm{NF}-\kappa \mathrm{B}$ activity may act as a therapeutic strategy for COPD treatment $(6,14)$.

Club cell secretory protein $(\mathrm{CC} 16)$ is a secretory protein with anti-inflammatory and immunomodulatory effects (15). CC16 is expressed primarily by non-ciliated bronchiolar epithelial cells, known as club cells (16). CC16 is also synthesized by the epithelial lining of the nose (17). Exaggerated airway inflammation has been reported in CC16 knockout mice compared with wild-type mice (18). Reduced levels of CC16 in the bronchoalveolar lavage fluid (BALF) have been reported to be associated with various lung disorders, including asthma and COPD $(19,20)$. Our previous study revealed that recombinant rat $\mathrm{CC} 16$ protein $(\mathrm{rCC} 16)$ exerted an anti-inflammatory effect by inhibiting the expression of MMP-9 and pro-inflammatory cytokines in epithelial cells and macrophages $(21,22)$. Given the anti-inflammatory function of $\mathrm{rCC} 16$, the aim of the present study was to investigate the effects of rCC16 on CS-induced lung inflammation in mice and the possible mechanism through which rCC16 suppresses CS-induced lung inflammation.

\section{Materials and methods}

Animals. Adult male C57/BL6 mice (6-8 weeks old; weight, 18-20 g) were purchased from the Laboratory Animal Center of Shanxi Medical University (Shanxi, China) and were maintained under specific pathogen-free conditions in a 12-h light-dark cycle with food and water provided ad libitum. All experiments were approved by the Animal Ethics Committee of Shanxi Medical University (Permit no. SXMU-2014-16) and carried out according to the guidelines of the National Institutes of Health Guide for the Care and Use of Laboratory Animals (NIH publication no. 85-23, revised 1996) (23).

Generation of COPD mice and rCC16 treatment . The COPD mouse model was prepared as previously described (24). Briefly, mice were divided into three groups (10 mice/group), including a control group, COPD group and rCC16 treatment group. For CS exposure, the mice were exposed (whole body) to smoke produced by six commercially filtered cigarettes, whose filters were removed before lighting, (Daguang brand, $1.3 \mathrm{mg}$ nicotine, $13 \mathrm{mg}$ tar and $15 \mathrm{mg}$ carbon monoxide per cigarette; Shanxi Kunming Tobacco Co., Ltd., Taiyuan, China) in a 271 chamber (plexiglass, self-made, 3x3x3 m) for $2 \mathrm{~h}$ /day, 5 days/week for 24 weeks. rCC16 was prepared according to our published method, and the biological activity of rCC16 was measured by analyzing the activity of phospholipase $\mathrm{A}_{2}$, the substrate of $\mathrm{CC} 16$ (12). During the last month of the study, rCC16-treated mice were treated intranasally with $2.5 \mu \mathrm{g} / \mathrm{g} /$ body weight rCC16 [dissolved in $20 \mu \mathrm{l}$ sterile phosphate-buffered saline (PBS); $10 \mu l$ to each nostril] each day prior to CS exposure as previously described $(25,26)$. Control animals were exposed to normal room air for 24 weeks. CS-exposed mice and control mice were instilled with $20 \mu 1$ sterile PBS intranasally (10 $\mu$ l to each nostril) each day during the last month. Mice were weighed before they were sacrificed.
Collection of blood and BALF. After anesthetization with sodium pentobarbital ( $75 \mathrm{mg} / \mathrm{kg}$ body weight), blood samples were collected from 5 mice in group via retro-orbital plexus puncture and stored at $-20^{\circ} \mathrm{C}$ for analysis. The chest wall was removed and the left bronchus was ligated with a silk suture (0.5 mm; Bangshan Medtec, Guangzhou, China). The trachea was cannulated using an intravenous catheter (20G Intima; Sanxin Medtec, Jiangxi, China), and the right lung was gently lavaged 1 time via a tracheal cannula with $1 \mathrm{ml}$ ice-cold PBS, followed by 4 times with $1 \mathrm{ml}$ PBS. BALF was collected and centrifuged at $290 \mathrm{x} \mathrm{g}$ for $10 \mathrm{~min}$ at $4^{\circ} \mathrm{C}$. Supernatants of the first fraction were stored at $-80^{\circ} \mathrm{C}$ for subsequent analysis of inflammatory cytokines using ELISA. BALF cells from the five different fractions were combined and resuspended in $500 \mu \mathrm{l}$ PBS. The total number of cells was counted using a hemocytometer. A differential cell count was performed using Wright-Giemsa (Sigma-Aldrich; Merck KGaA, Darmstadt, Germany) staining for cytological determination. Finally, tissues of the left lung were removed and stored at $-70^{\circ} \mathrm{C}$ for mRNA analysis.

Lung histological analysis. After anesthetization, the chest wall was removed from another five mice in each group. BALF cells from the right lung of each animal were collected as described above for further analysis. The right bronchus was ligated and the left lung was perfused with $4 \%$ paraformaldehyde through the main left bronchus before it was immersed and maintained in $4 \%$ paraformaldehyde for another $24 \mathrm{~h}$. The tissue was embedded in paraffin, and $5-\mu \mathrm{m}$ thick sections were prepared. The mean linear intercept (MLI) and the mean alveolar number (MAN) were visualized using hematoxylin and eosin (H\&E) staining, and this was assessed in five randomly selected fields on each slice by Image-Pro Plus 6.0 (Media Cybernetics, Inc., Rockville, MD, USA). One investigator was responsible for inflating the lung with paraformaldehyde and two blinded investigators analyzed the MLI and MAN in order to avoid observer bias.

Immunohistochemistry. Immunohistochemical analysis based on the streptavidin-biotin complex was performed as previously described (27). The primary antibodies were CC16 (1:250) and NF-кB/p65 (1:100; both from Santa Cruz Biotechnology, Inc., Dallas, TX, USA). Horseradish peroxidase-conjugated secondary antibodies were obtained from Beijing Zhongshan Jinqiao Biotechnology Co., Ltd. (Beijing, China). The appearance of a tan color indicated positive staining for the target protein, and staining was analyzed using Leica QWin image processing software (Leica Microsystems GmbH, Wetzlar, Germany). Data are presented as the gray value mean \pm standard deviation (SD), and a higher gray value corresponds to lower protein expression.

Gene expression analysis by RT-qPCR. RNA was isolated from mouse lung tissues (whole lung) using the RNApure Tissue \& Cell kit (CWBIO, Beijing, China) according to the manufacturer's protocols and was reverse transcribed using a Reverse Transcription kit (CWBIO). For gene expression analysis, RT-qPCR was performed using UltraSYBR mixture (CWBIO) and each reaction was performed in duplicate. The averages of the obtained $\mathrm{Ct}$ values were used for further calculations. 
Gene expression levels were normalized to the expression of the reference gene, $\beta$-actin. Gene expression levels were calculated using the comparative $\mathrm{Ct}$ method $\left(2^{-\Delta \Delta C t}\right)(28)$. The primer sequences are the same as in a previous study (22).

Determining the levels of cytokines. Serum and BALF levels of tumor necrosis factor (TNF)- $\alpha$, interleukin (IL)- 6 and IL-8 proteins were measured using an ELISA kit (Shanghai Westang Bio-Tech. Co., Ltd., Shanghai, China) according to the manufacturer's instructions. The BALF CC16 level was measured using ELISA (Qiaodu Biotechnology, Shanghai, China) according to the manufacturer's protocols.

Immunoblotting. An NE-PER Nuclear and Cytoplasmic Extraction kit (Thermo Fisher Scientific, Inc., Waltham, MA, USA) was used to extract nuclear and cytoplasmic proteins from BALF cells and proteins were quantified using the BCA protein assay reagent. The total protein was prepared using SDS lysis buffer containing $50 \mathrm{mM}$ Tris- $\mathrm{HCl}(\mathrm{pH}$ 6.8), $10 \%$ glycerol and $2 \%$ SDS. Proteins $(20 \mu \mathrm{g})$ were loaded onto a $12 \%$ SDS-PAGE gel, separated and transferred onto a polyvinylidene fluoride (PVDF) membrane. The membrane was blocked with 5\% skimmed milk, incubated overnight with the indicated primary antibodies at $4^{\circ} \mathrm{C}$ and then incubated with an anti-rabbit HRP-conjugated IgG antibody for $1 \mathrm{~h}$ at room temperature. Protein bands were visualized using the ECL blot detection system (CWBIO). Lamin B and $\beta$-actin prime antibodies (Cell Signaling Technology, Inc., Danvers, MA, USA) served as references to detect nuclear proteins, total protein and cytosolic proteins.

Electrophoretic mobility shift assay (EMSA). Nuclear proteins were extracted from lung tissues and incubated with a biotin-labelled double-stranded oligonucleotide containing the consensus sequence of NF- $\mathrm{KB}-\mathrm{DNA}$ binding site (5'-AGTTGAGGGGACTTTCCCAGG-3') as previously described (29). Binding reaction mixtures $(20 \mu \mathrm{l})$, containing $8 \mu \mathrm{g}$ nuclear extract protein, $1 \mu \mathrm{g}$ poly(dI-Dc) (Thermo Fisher Scientific, Inc.) and 20 ficomoles biotin-labeled probe in binding buffer (10 mM Tris, $50 \mathrm{mM}$ potassium chloride, $1 \mathrm{mM}$ dithiothreitol, $0.1 \mathrm{mM}$ EDTA, 2.5\% glycerol and $5 \mathrm{mM}$ magnesium chloride) were incubated for $20 \mathrm{~min}$ at room temperature. DNA-protein complexes were resolved on $6 \%$ non-denaturing polyacrylamide gels and blotted onto a Biodyne B (pore size, $0.45 \mu \mathrm{m}$ ) positively charged nylon membrane (Thermo Fisher Scientific, Inc.). Bands were detected by chemiluminescence using the LightShift Chemiluminescent EMSA kit according to the manufacturer's instructions (Thermo Fisher Scientific, Inc.).

Statistical analysis. Data are presented as the mean \pm standard deviation. One-way ANOVA followed by the S-N-K method was used for two-group comparisons. All statistical analyses were conducted using GraphPad Prism software (GraphPad Software, Inc., La Jolla, CA, USA). Differences with $\mathrm{P}<0.05$ were considered to be statistically significant.

\section{Results}

rCC16 attenuates pathological changes in lung tissues. The amino acid sequences for mouse and rat CC16 were analyzed using DNAMAN software. The alignment showed that mouse and rat CC16 shared a $89.58 \%$ homology (Fig. 1A).

CS exposure for 24 weeks resulted in the typical pathological features of COPD, with major enlargement of alveolar spaces distributed throughout the parenchyma. rCC16 treatment could reduce the degree of alveolar enlargement, and lung structures in the control group were normal. H\&E staining also revealed that, compared with exposure to CS alone, rCC16 administration alleviated the influx of inflammatory cells, which was characterized by a large number of neutrophils and macrophages in the alveolar spaces (Fig. 1B). Quantitative morphological analysis showed that MLI was much higher in CS-exposed mice $(45.62 \pm 1.036 \mu \mathrm{m})$ compared with normal mice $(31.49 \pm 0.2619 \mu \mathrm{m})$, and that $\mathrm{rCC} 16$ could decrease the MLI (39.37 $\pm 0.5287 \mu \mathrm{m}$; Fig. 1C). Additionally, quantitative morphological analysis showed that MAN was significantly decreased in CS mice $\left(384.3 \pm 26.35 / \mathrm{mm}^{2}\right)$ compared with the normal group $\left(604.4 \pm 15.63 / \mathrm{mm}^{2}\right)$, and rCC16 treatment increased MAN $\left(506.7 \pm 18.36 / \mathrm{mm}^{2}\right.$; Fig. 1D). rCC16 treatment also led to increased body weight compared with CS mice (Fig. 1E). These data demonstrate that a CS-induced mouse COPD model was successfully established and that $\mathrm{rCC} 16$ was able to attenuate pathological changes in the lungs induced by CS exposure.

rCC16 attenuates the expression of TNF- $\alpha, I L-6$ and $I L-8$ in CS-exposed mice. CC16 is known to possess anti-inflammatory properties (30). In order to determine the potential effect of $\mathrm{rCC} 16$ on the expression of pro-inflammatory cytokines, a mouse model of COPD was established and mice were treated with rCC16. Cytokine mRNA expression in the lungs and cytokine protein levels in the serum and BALF were analyzed using qPCR and ELISA assays, respectively. Compared with control mice, exposure to CS markedly increased the production of TNF- $\alpha$, IL-6 and IL-8 (Fig. 2), and CS-stimulated overexpression of cytokines was inhibited by $\mathrm{rCC} 16$ at the mRNA (Fig. 2A-C) and protein levels (Fig. 2D-F). These results suggest that rCC16 effectively suppressed the production of pro-inflammatory cytokines in CS-exposed mice.

rCC16 inhibits the nuclear translocation and DNA binding of $N F-\kappa B / p 65$. Pro-inflammatory cytokines are secreted from the endothelium and immunocytes in response to various stimuli $(31,32)$. The total number of leukocytes, neutrophils, macrophages and lymphocytes in BALF was assessed. As shown in Table I, the CS-exposed group exhibited a significant increase in the number of neutrophils, lymphocytes, macrophages and total cells compared with the control group. rCC16 treatment reduced the total number cells and macrophages in BALF but had no effect on neutrophils and lymphocytes. Endogenous CC16 expression in club cells distributed throughout the respiratory tract was measured using immunohistochemical analysis, and levels of secreted CC16 in BALF were analyzed using ELISA. Immunohistochemistry showed that $\mathrm{CC} 16$ was mainly expressed in bronchial epithelial cells and that CS exposure led to a decrease in $\mathrm{CC} 16$ expression, while $\mathrm{rCC} 16$ treatment ameliorated this effect. However, rCC16 treatment did not completely rescue the level of endogenous CC16 compared with the control group (Fig. 3A and B). ELISA analysis showed that CS exposure decreased CC16 
A

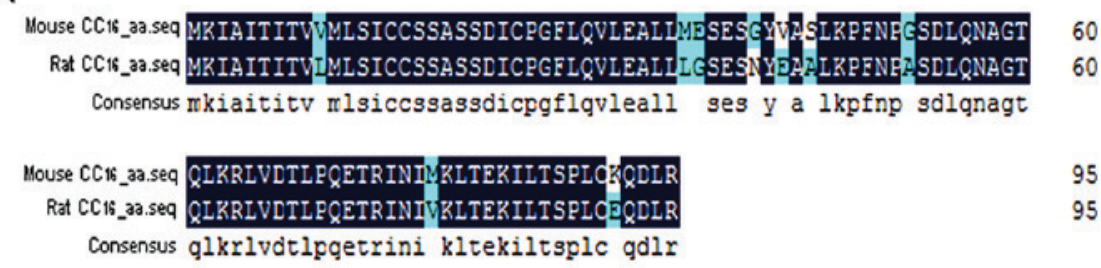

B

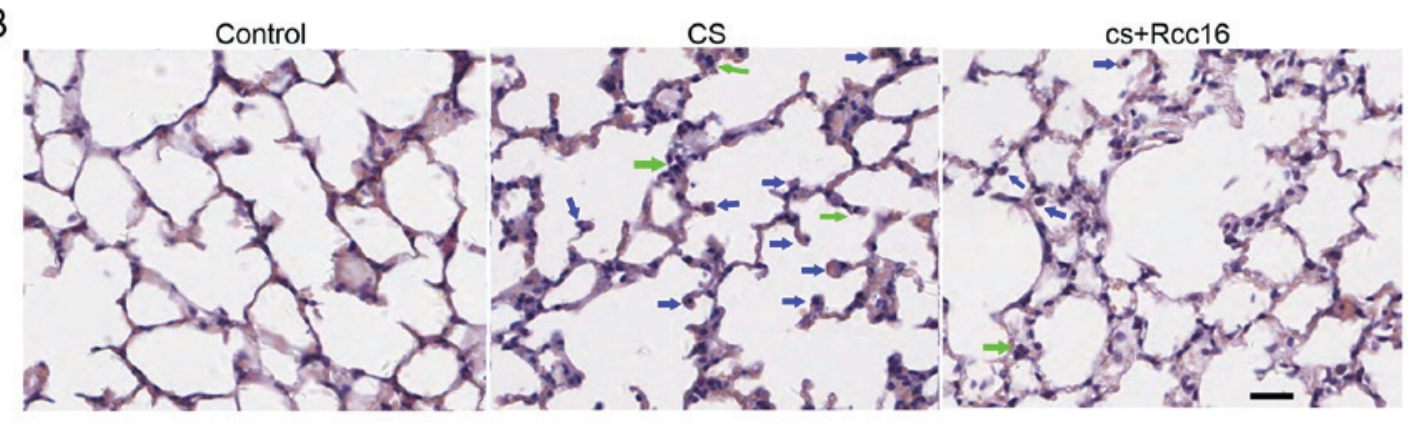

C

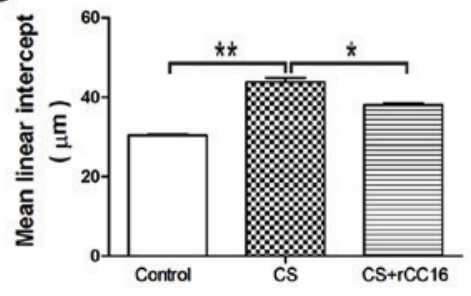

$\mathrm{D}$

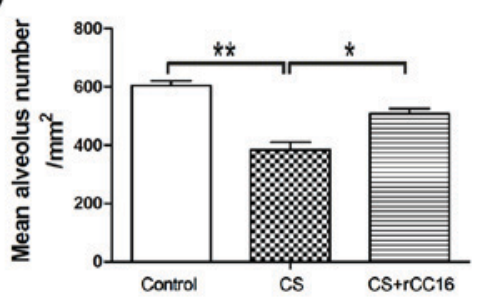

$\mathrm{E}$

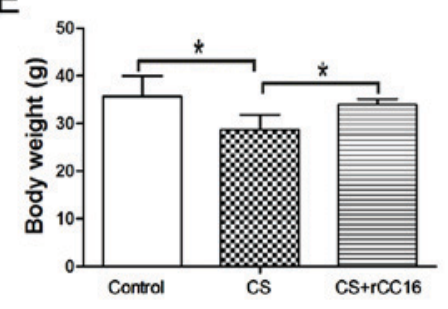

Figure 1. rCC16 ameliorates CS-induced pathological changes in the lungs of COPD mice. (A) Amino acid sequences of mouse CC16 (NP_035811.1) and rat CC16 (NP_037183.1) were aligned using DNAMAN (Lynnon, Quebec, Canada). The degree of homology is indicated by different colors. Black, 100\%; blue, $50 \%$. (B) H\&E-stained lung sections from control mice, CS-exposed mice and rCC16-treated mice. Exposure to CS induced the infiltration of inflammatory cells into the lungs, as indicated by arrows (neutrophils, green; macrophages, blue). Treatment with rCC16 reduced the degree of pulmonary inflammation, as indicated by arrows. (C) rCC16 reduced the mean linear intercept, which was increased by CS exposure. (D) rCC16 augmented the mean alveolar number, which was decreased by CS exposure. (E) rCC16 treatment led to an increase in body weight, which was significantly reduced in CS-exposed mice. Data are presented as the mean $\pm \mathrm{SD}$ (n=5/group). ${ }^{*} \mathrm{P}<0.05$ and ${ }^{* *} \mathrm{P}<0.01$ as indicated. Scale bars represent $50 \mu \mathrm{m}$. COPD, chronic obstructive pulmonary disease; CS, cigarette smoke; rCC16, recombinant club cell secretory protein; SD, standard deviation.

A

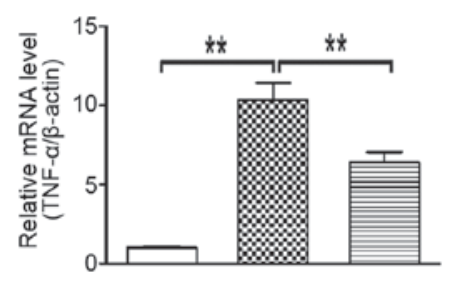

D

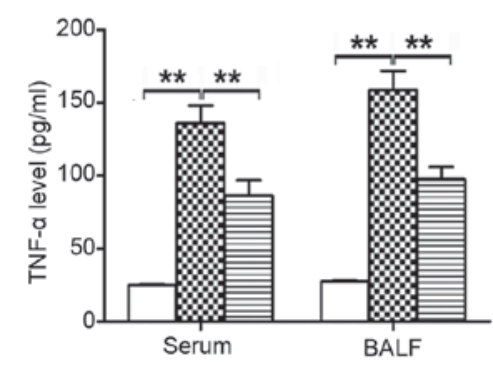

$\mathrm{B}$

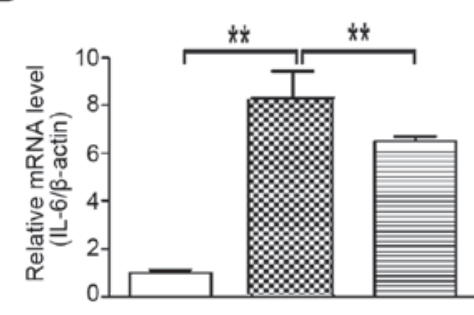

E

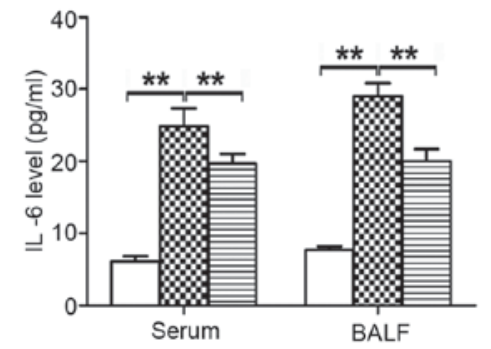

C

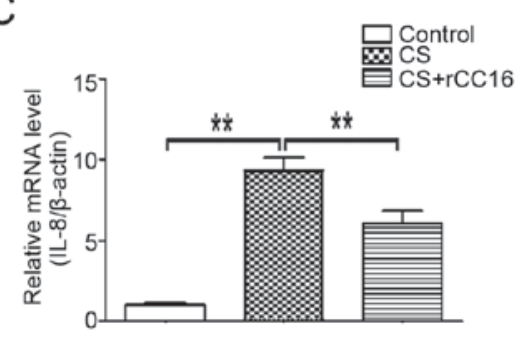

$\mathrm{F}$

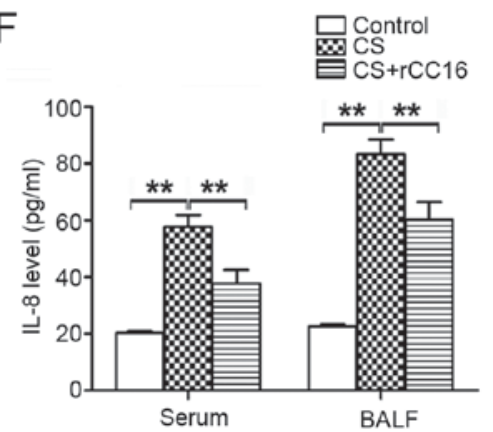

Figure 2. Effects of rCC16 on TNF- $\alpha$, IL-6 and IL-8 expression in CS-exposed mice. The expression of TNF- $\alpha$, IL-6 and IL-8 (A-C) mRNA and (D-F) protein in CS-exposed mice treated with rCC16. mice were exposed to CS for 24 weeks and treated intranasally with rCC16 for the last 4 weeks. For qPCR measurements, the results are expressed as ratios of $2^{-\Delta \Lambda C t}$ values for TNF- $\alpha$, IL- 6 and IL- $8 \mathrm{mRNA} / \beta$-actin. For ELISA measurements, results are expressed as the absolute protein values of TNF- $\alpha$, IL- 6 and IL- 8 . Data are presented as the mean $\pm \mathrm{SD}$ ( $\mathrm{n}=5 /$ group). ${ }^{.} \mathrm{P}<0.05$ and ${ }^{* * *} \mathrm{P}<0.01$ as indicated. BALF, bronchoalveolar lavage fluid; CS, cigarette smoke; rCC16, recombinant club cell secretory protein; SD, standard deviation. 
A

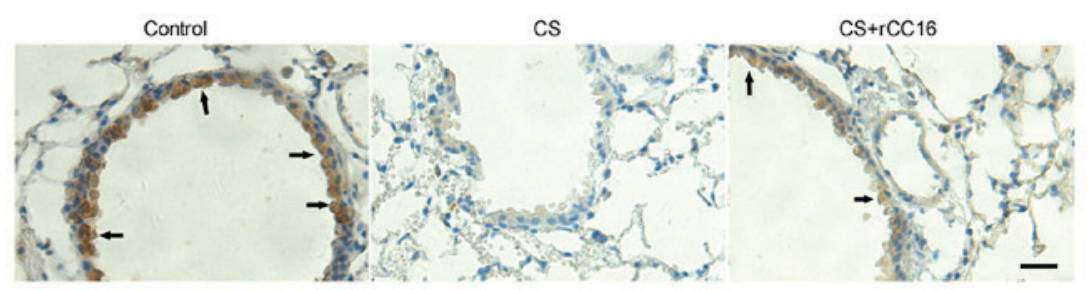

B

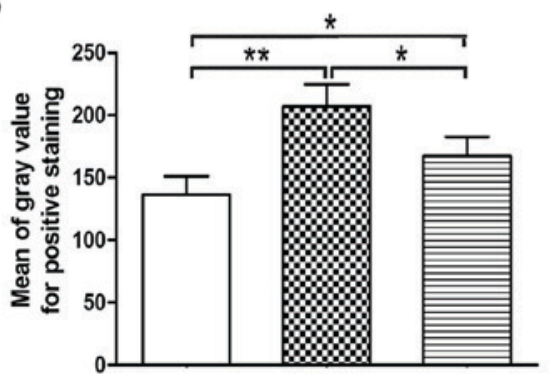

C

D

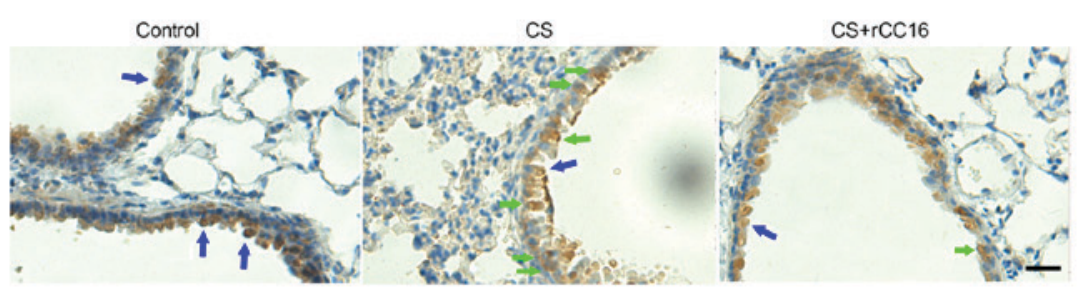

E

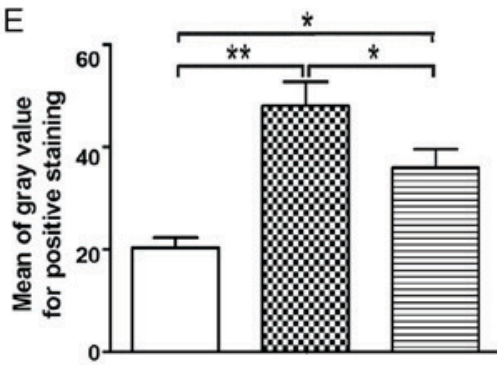

$\mathrm{F}$

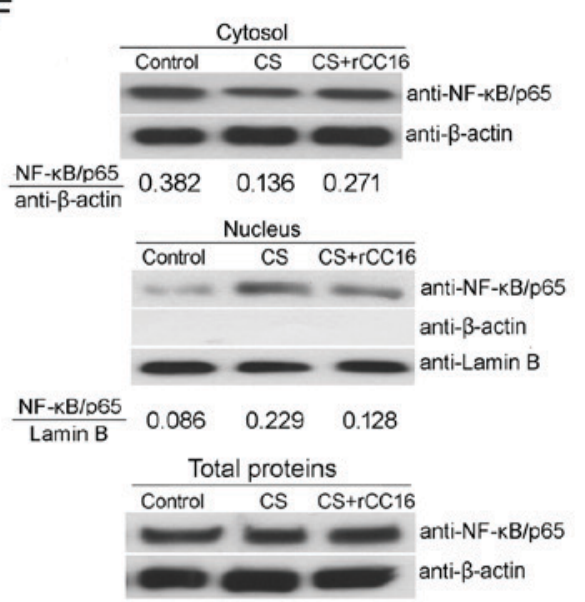

G

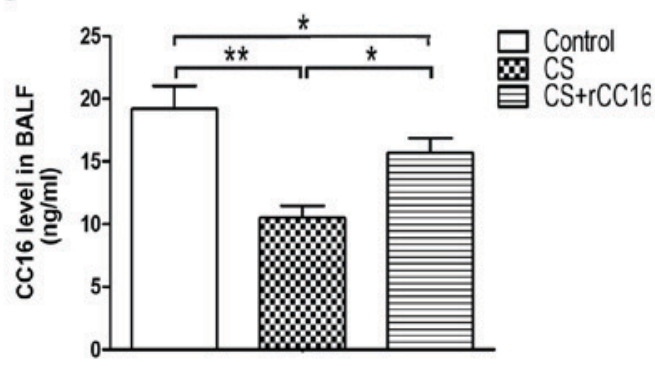

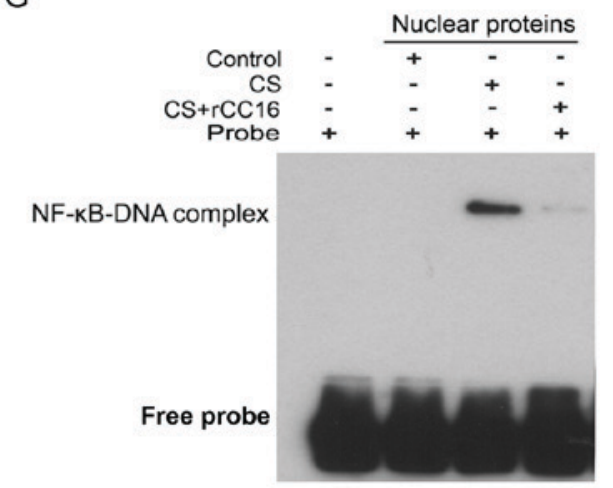

Figure 3. rCC16 promotes endogenous CC16 expression and inhibits nuclear translocation and DNA binding of NF-kB/p65. (A) Endogenous CC16 expression in lung alveolar epithelial cells from each group was determined using immunohistochemical staining. Arrows indicate positive staining. (B) The intensity of positive staining was evaluated and data are expressed as the mean $\pm \mathrm{SD}$ ( $\mathrm{n}=5 / \mathrm{group}$ ). (C) Endogenous CC16 levels in BALF were determined by ELISA. Data are presented as the mean $\pm \mathrm{SD}$ ( $\mathrm{n}=5 /$ group). (D) Subcellular distribution of NF- $\mathrm{kB} / \mathrm{p} 65$ in the bronchial epithelium, as detected by immunohistochemical staining. (Blue arrows indicate positive cytoplasmic staining; green arrows indicate positive nuclear staining). (E) The intensity of positive staining was evaluated by the gray value, and data are expressed as the mean $\pm \mathrm{SD}$ (n=5/group). (F) The distribution of NF-kB/p65 in BALF cells was determined by immunoblotting. Potential contamination of the nuclear fractions by cytoplasmic fractions was checked and excluded. One representative experiment is shown. Lamin B and $\beta$-actin were used as internal loading controls for the nuclear fraction and the cytoplasmic fraction, respectively. (G) DNA binding of NF- $\mathrm{B} / \mathrm{p} 65$ was assessed by EMSA. One representative experiment is shown. ${ }^{*} \mathrm{P}<0.05$ and ${ }^{* * *} \mathrm{P}<0.01$ as indicated. Scale bars represent $40 \mu \mathrm{m}$. BALF, bronchoalveolar lavage fluid; CS, cigarette smoke; rCC16, recombinant club cell secretory protein; SD, standard deviation. 
Table I. BALF cells analyzed by Wright-Giemsa staining.

\begin{tabular}{lccr}
\hline Cells & Control & CS & CS+rCC16 \\
\hline Total cells $\left(\times 10^{5} / \mathrm{ml}\right)$ & $3.60 \pm 1.18$ & $14.93 \pm 4.79^{\mathrm{a}}$ & $10.57 \pm 3.89^{\mathrm{b}}$ \\
Macrophages $\left(\times 10^{5} / \mathrm{ml}\right)$ & $3.57 \pm 1.09$ & $14.53 \pm 4.04^{\mathrm{a}}$ & $10.91 \pm 4.31^{\mathrm{b}}$ \\
Neutrophils $\left(\mathrm{x} 10^{5} / \mathrm{ml}\right)$ & 0 & $0.38 \pm 0.03^{\mathrm{a}}$ & $0.33 \pm 0.02$ \\
Lymphocytes $\left(\times 10^{5} / \mathrm{ml}\right)$ & $0.02 \pm 0.01$ & $0.31 \pm 0.06^{\mathrm{a}}$ & $0.30 \pm 0.01$ \\
\hline
\end{tabular}

Data are expressed as the mean \pm SEM (for $n=5 /$ treatment group). Statistical analysis was performed using one-way ANOVA followed by a $\mathrm{S}-\mathrm{N}-\mathrm{K}$ Multiple Comparison test ( ${ }^{\mathrm{a}} \mathrm{P}<0.01$ vs. Control, ${ }^{\mathrm{b}} \mathrm{P}<0.05$ vs. CS group).

expression, while rCC16 treatment increased the level of $\mathrm{CC} 16$ in BALF (Fig. 3C).

Our previous studies showed that rCC16 inhibits an inflammatory mediator via the $\mathrm{NF}-\kappa \mathrm{B}$ pathway $(21,22)$. To determine whether the $\mathrm{NF}-\kappa \mathrm{B}$ pathway is also involved in the regulation of TNF- $\alpha$, IL- 6 and IL- 8 expression by rCC16 in CS-exposed mice, we investigated the distribution of NF- $\mathrm{B} / \mathrm{p} 65$ in bronchiolar epithelial and BALF cells. As shown in Fig. 3D and E, NF- $\mathrm{B} / \mathrm{p} 65$ in the nuclei of bronchial airway epithelial cells was increased in CS-exposed mice, and this was significantly reduced by rCC16 treatment. Additionally, NF- $\kappa \mathrm{B} / \mathrm{p} 65$ was upregulated in the nuclei of BALF cells and this was significantly ameliorated by $\mathrm{rCC} 16$ treatment. NF- $\kappa \mathrm{B} / \mathrm{p} 65$ levels in the cytosol were decreased in CS-exposed BALF cells. Treatment with rCC16 ameliorated this decrease without affecting the total cellular levels of NF- $\kappa \mathrm{B} / \mathrm{p} 65$ (Fig. 3F). Moreover, to further verify the inhibitory effect of $\mathrm{rCC} 16$ on $\mathrm{NF}-\kappa \mathrm{B}$ activity, EMSA was employed to determine whether rCC16 inhibited the DNA binding activity of $\mathrm{NF}-\kappa \mathrm{B}$. As shown in Fig. 3G, CS exposure markedly augmented the DNA binding activity of $N F-\kappa B$, and rCC16 suppressed CS-induced NF- $\mathrm{NB}-\mathrm{DNA}$ binding. These findings indicate that $\mathrm{rCC} 16$ suppresses the activity of $\mathrm{NF}-\kappa \mathrm{B}$ by inhibiting nuclear translocation and blocking binding to DNA.

\section{Discussion}

The primary characteristic of COPD is restricted pulmonary airflow. This is typically progressive and is associated with an abnormal inflammatory response to the inhalation of noxious particles and gases. CS is a complex mixture of oxidant radicals and different chemical compounds, including reactive aldehydes and semiquinones. CS is widely recognized as a primary risk factor that is associated with the progression of COPD (33).

CC16 is a secretory protein release by club cells, which are present throughout the respiratory tract epithelium from the nose to the respiratory bronchioles. CC16 possesses anti-inflammatory and immunomodulatory properties (34). Bernard et al (35) first reported that CC16 levels in the serum and BALF were significantly reduced in COPD patients compared with non-smoker controls. In addition, markedly decreased serum levels of CC16 were detected in healthy smokers and COPD patients compared with non-smoker controls (36). The expression of $\mathrm{CC} 16$ in the airway was inversely correlated with the severity of airflow obstruction in COPD patients (37), and patients with COPD GOLD stages III-IV have a much lower expression of $\mathrm{CC} 16$ in the airway epithelium compared with patients with COPD GOLD I-II (38). Notably, increased CC16 levels in the BALF and plasma samples were found to be associated with improved bronchial dysplasia following smoking cessation (39). In mouse models of chronic CS exposure, decreased CC16 expression was detected in the airway epithelium (38). Using the $\mathrm{CC} 16$-deficient $\left(\mathrm{CC}^{-/-}\right)$mouse model, Zhu et al (40) reported the enlargement of alveolar airspaces and increased lung inflammatory cell counts in $\mathrm{CC} 16^{-/}$mice exposed to CS compared with wild-type mice that were exposed to CS. Together, these studies suggest that CC16 serves a role in the progression of COPD. However, the underlying mechanism of CC16 remains unclear.

As CC16 has anti-inflammatory properties $(22,38)$, several groups have attempted to use $\mathrm{CC} 16$ augmentation approaches to treat inflammatory diseases, including COPD. It has been reported that adenoviral-mediated CC16 overexpression in airway epithelial cells in mice that were acutely exposed to CS resulted in reduced $\mathrm{CS}$-induced lung inflammation, and that this effect is associated with reduced activation of $N F-\kappa B$ in the lung (38). rCC16 protein was delivered to infants via the intra-tracheal route, and markers of acute lung inflammation and injury were reduced (26). The recombinant human CC16 protein had also been applied to respiratory distress syndrome and acute lung injury models; promising anti-inflammatory effects were reported $(25,41)$. In our previous study, recombinant rat $\mathrm{CC} 16$ protein was demonstrated to have biological activity (21). There is an $89.58 \%$ similarity in the amino acid sequences of mouse and rat CC16 proteins. Importantly, rCC16 has been used as an anti-inflammatory mediator in lipopolysaccharide-activated mouse macrophages (RAW264.7) in vitro (22). In the present study, a mouse model of COPD was prepared by chronically exposing mice to CS. Moreover, rCC16 was delivered via intranasal instillation. The anti-inflammatory effects of CC16 were evaluated and its underlying mechanism was investigated.

The administration of anti-inflammatory reagents via a nasal route to treat respiratory inflammation has been reported to be beneficial $(42,43)$. In the present study, a murine COPD model was established by exposure to CS for 24 weeks, and it was found that COPD mice displayed the hallmarks of COPD, including enlarged alveolar spaces, increased MLI and decreased MAN. When $\mathrm{rCC} 16$ was administered intranasally, pathological impairment in CS-exposed mice was 
alleviated (Fig. 1). However, the present study is not without limitations; the pulmonary function test was not performed as the equipment was unavailable. Since lung structure can partially represent the change of pulmonary function, we evaluated the structure of the lungs by analyzing pathological alterations (MLI and MAN) after CS exposure in the presence and absence of rCC16 treatment.

Pro-inflammatory cytokines serve an important role in the development of COPD. TNF- $\alpha$ can trigger the activation of other pro-inflammatory cytokines, such as IL-6 and IL-8 (44). Both IL- 6 and IL- 8 are involved in regulating the recruitment and activation of neutrophils to regulate neutrophilic inflammation (45). Along with damage to the lung parenchyma, increased TNF- $\alpha$, IL- 6 and IL- 8 were observed in the BALF and serum of CS-exposed mice. In contrast, rCC16 treatment downregulated pro-inflammatory cytokines in both the serum and BALF (Fig. 2).

Pro-inflammatory cytokines are produced by both epithelial cells and immune cells. The accumulation of inflammatory cells, such as macrophages, neutrophils and lymphocytes, is seen in BALF from CS-exposed mice. Among these cells, the number of macrophages is markedly increased in CS-exposed mice. It is known that an increased number of macrophages in the airway lumen are involved in the inflammatory responses of COPD, and anti-inflammation treatment is a primary strategy for COPD $(46,47)$. In the present study, we found that $\mathrm{rCC} 16$ administration decreased the number of macrophages. Previous studies $(21,22,38)$ have revealed that CC16 functions as an anti-inflammation mediator via the $\mathrm{NF}-\kappa \mathrm{B}$ pathway. First, the levels of endogenous CC16 in BALF and club cells were analyzed using ELISA and immunohistochemistry. Our data showed that rCC16 treatment upregulated endogenous CC16 in both BALF and club cells, which were reduced in CS-exposed mice. In our previous studies, ultrastructural damage was observed in club cells and a reduced number of club cells were detected in the CS-exposed rats. Moreover, the levels of CC16 protein and mRNA were also decreased in lung tissues from CS-exposed rats $(48,49)$. Therese results suggest that CS exposure damages club cells and affected the synthesis of CC16. Notably, exogenous delivery of rCC16 limited injury to club cells and increased CC16 expression in the airway $(48,49)$.

Nuclear translocation of $\mathrm{NF}-\kappa \mathrm{B} / \mathrm{p} 65$, which is known to activate the $\mathrm{NF}-\kappa \mathrm{B}$ signaling pathway (48), was assessed. Immunohistochemistry showed that CS exposure increased the nuclear distribution of $\mathrm{NF}-\kappa \mathrm{B} / \mathrm{p} 65$ in bronchial epithelial cells, and the administration of $\mathrm{rCC} 16$ reversed this effect. Immunoblotting also showed that CS exposure promoted nuclear translocation of $\mathrm{NF}-\kappa \mathrm{B} / \mathrm{p} 65$ in BALF cells, and $\mathrm{rCC} 16$ treatment reversed this translocation. Additionally, EMSA further demonstrated that $\mathrm{rCC} 16$ suppressed $\mathrm{CS}$-induced $\mathrm{NF}-\kappa \mathrm{B}-\mathrm{DNA}$ binding. All these findings indicate that $\mathrm{rCC} 16$ suppresses the activity of $\mathrm{NF}-\kappa \mathrm{B}$, which was activated by $\mathrm{CS}$ exposure, by inhibiting its nuclear translocation and blocking its binding with DNA. Other studies showed that NF- $\kappa \mathrm{B}$ was expressed and activated in club cells in rats with induced respiratory inflammation that were exposed to hexavalent chromium (49). Nuclear translocation of the NF- $\kappa$ B p65 subunit and activation of $\mathrm{NF}-\kappa \mathrm{B}$ were observed in respiratory syncytial virus-infected human club-like lung (H441) cells (50). However, it was reported that CC16 does not interact

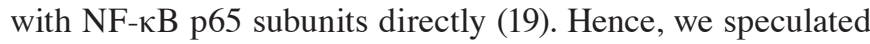
that $\mathrm{CC} 16$ may be directly or indirectly involved in regulating I $\kappa \mathrm{B}-\alpha$ phosphorylation, which is normally present in the cytosol and forms complexes with $\mathrm{NF}-\kappa \mathrm{B}$ dimers, thereby preventing the nuclear localization of $\mathrm{NF}-\kappa \mathrm{B}$ and ensuring a low basal transcriptional activity (51). This hypothesis needs to be investigated further.

Our present findings are in agreement with those of previous studies $(30,38)$ which showed that airway CC16 expression was decreased in CS-induced COPD murine model, CC16 deficiency promoted CS-induced airspace enlargement and pulmonary inflammation, and that these changes were associated with increased $\mathrm{NF}-\kappa \mathrm{B}$ activation. Moreover, all of these studies revealed that $\mathrm{CS}$-induced pulmonary inflammation and injury were reversed by $\mathrm{CC} 16$ augmentation. Here we further revealed that $\mathrm{CC} 16$ augmentation reduced $\mathrm{NF}-\kappa \mathrm{B}$ activation not only in lung tissue, but also in bronchiolar epithelial and BALF cells. These findings may better explain the possible mechanism of how CC16 acts in the development of COPD.

In the present study, CS-exposure led to a decrease in body weight in COPD mice, and $\mathrm{rCC} 16$ treatment partially reversed the effect. Here, we speculate that this may be because CS exposure leads to dysfunction of respiratory muscles and causes malnutrition in COPD mice. By contrast, rCC16 treatnent inhibits inflammaton in the lungs and improves the strength and endurance of respiratory muscles. The recovery of lung fuction may ameliorate nutritional imbalance in COPD mice (52). In summary, our results suggest that the administration of rCC16 alleviates pathological lung injuries and decreases the production of pro-inflammatory cytokines in CS-exposed mice by inactivating the $\mathrm{NF}-\kappa \mathrm{B}$ pathway. The anti-inflammatory effects exerted by rCC16 suggest that it may have potential as a treatment for COPD. However, further studies should be conducted to determine the underlying mechanisms of rCC16 to contribute to the discovery of new therapeutic agents for COPD treatment.

\section{Acknowledgements}

Not applicable.

\section{Funding}

The present study was supported by the Research Project Supported by Shanxi Scholarship Council of China (grant no. 2015-101), the Fund Program for the Scientific Activities of Selected Returned Overseas Professionals in Shanxi Province (grant no. 2016-097) and the Startup Foundation for Doctors of Shanxi Medical University (grant no. 03201539).

\section{Availability of data and materials}

All data generated or analyzed during this study are included in this published article.

\section{Authors' contributions}

MP conceived and designed the experiments. TL, DW, HYL and XYH performed the experiments. BFY and XRZ 
analyzed and interpreted the data. RG and HLW contributed in designing the present study and drafted the manuscript. All authors read and approved the final manuscript.

\section{Ethics approval and consent to participate}

All animal experiments were approved by the Animal Ethics Committee of Shanxi Medical University (Taiyuan, China).

\section{Patient consent for publication}

Not applicable.

\section{Competing interests}

The authors declare that they have no competing interests.

\section{References}

1. Khan MA, Kianpour S, Stämpfli MR and Janssen LJ: Kinetics of in vitro bronchoconstriction in an elastolytic mouse model of emphysema. Eur Respir J 30: 691-700, 2007.

2. Van Dijk EM, Culha S, Menzen MH, Bidan CM and Gosens R: Elastase-induced parenchymal disruption and airway hyper responsiveness in mouse precision cut lung slices: Toward an ex vivo COPD model. Front Physiol 7: 657, 2016.

3. Rabe KF, Hurd S, Anzueto A, Barnes PJ, Buist SA, Calverley P, Fukuchi Y, Jenkins C, Rodriguez-Roisin R, van Weel C, et al: Global strategy for the diagnosis, management and prevention of chronic obstructive pulmonary disease: GOLD executive summary. Am J Respir Crit Care Med 176: 532-555, 2007.

4. Hogg JC, Chu F, Utokaparch S, Woods R, Elliott WM, Buzatu L, Cherniack RM, Rogers RM, Sciurba FC, Coxson HO and Paré PD: The nature of small-airway obstruction in chronic obstructive pulmonary disease. N Engl J Med 350: 2645-2653, 2004

5. Barnes PJ: Alveolar macrophages as orchestrators of COPD. Copd 1: 59-70, 2004.

6. Barnes PJ: Inflammatory mechanisms in patients with chronic obstructive pulmonary disease. J Allergy Clin Immunol 138 16-27, 2016.

7. Di Marco F, Santus P, Scichilone N, Solidoro P, Contoli M, Braido F and Corsico AG: Symptom variability and control in COPD: Advantages of dual bronchodilation therapy. Respir Med 125: 49-56, 2017.

8. Barnes PJ: Corticosteroid resistance in patients with asthma and chronic obstructive pulmonary disease. J Allergy Clin Immunol 131: 636-645, 2013.

9. Lee JH, Koo TH, Yoon H, Jung HS, Jin HZ, Lee K, Hong YS and Lee JJ: Inhibition of NF-kappa B activation through targeting I kappa B kinase by celastrol, a quinone methide triterpenoid. Biochem Pharmacol 72: 1311-1321, 2006.

10. Park HJ, Kim IT, Won JH, Jeong SH, Park EY, Nam JH, Choi J and Lee KT: Anti-inflammatory activities of ent-16alphaH,17-hy droxy-kauran-19-oic acid isolated from the roots of Siegesbeckia pubescens are due to the inhibition of iNOS and COX-2 expression in RAW 264.7 macrophages via NF-kappaB inactivation. Eur J Pharmacol 558: 185-193, 2007.

11. Caramori G, Romagnoli M, Casolari P, Bellettato C, Casoni G, Boschetto P, Chung KF, Barnes PJ, Adcock IM, Ciaccia A, et al: Nuclear localisation of p65 in sputum macrophages but not in sputum neutrophils during COPD exacerbations. Thorax 58 348-351, 2003.

12. Di Stefano A, Caramori G, Oates T, Capelli A, Lusuardi M, Gnemmi I, Ioli F, Chung KF, Donner CF, Barnes PJ and Adcock IM: Increased expression of nuclear factor-kappaB in bronchial biopsies from smokers and patients with COPD. Eur Respir J 20: 556-563, 2002.

13. Zhuan B, Yu Y, Yang Z,Zhao X and Li P: Mechanisms of oxidative stress effects of the NADPH oxidase-ROS-NF- $\kappa \mathrm{B}$ transduction pathway and VPO1 on patients with chronic obstructive pulmonary disease combined with pulmonary hypertension. Eur Rev Med Pharmacol Sci 21: 3459-3464, 2017.
14. Edwards MR, Bartlett NW, Clarke D, Birrell M, Belvisi M and Johnston SL: Targeting the NF-kappaB pathway in asthma and chronic obstructive pulmonary disease. Pharmacol Ther 121: $1-13,2009$.

15. Nogaki T, Asano K, Furuta A, Kanai K, Suzaki I, Kanei A and Suzaki H: Enhancement of clara cell $10-\mathrm{kD}$ protein $(\mathrm{CC} 10)$ production from nasal epithelial cells by fexofenadine hydrochloride. Asian Pac J Allergy Immunol 30: 139-145, 2012.

16. Mukherjee AB, Kundu GC, Mantile-Selvaggi G, Yuan CJ, Mandal AK, Chattopadhyay S, Zheng F, Pattabiraman N and Zhang Z: Uteroglobin: A novel cytokine? Cell Mol Life Sci 55: 771-787, 1999.

17. Johansson S, Keen C, Ståhl A, Wennergren G and Benson M: Low levels of CC16 in nasal fluid of children with birch pollen-induced rhinitis. Allergy 60: 638-642, 2005.

18. Wang H, Long XB, Cao PP, Wang N, Liu Y, Cui YH, Huang SK and Liu Z: Clara cell 10-kD protein suppresses chitinase 3-like 1 expression associated with eosinophilic chronic rhinosinusitis. Am J Respir Crit Care Med 181: 908-916, 2010.

19. Long XB, Hu S, Wang N, Zhen HT, Cui YH and Liu Z: Clara cell $10-\mathrm{kDa}$ protein gene transfection inhibits NF- $\kappa \mathrm{B}$ activity in airway epithelial cells. PLoS one 7: e35960, 2012.

20. Van Vyve T, Chanez P, Bernard A, Bousquet J, Godard P, Lauwerijs R and Sibille Y: Protein content in bronchoalveolar lavage fluid of patients with asthma and control subjects. J Allergy Clin Immunol 95: 60-68, 1995.

21. Pang M, Wang H, Bai JZ, Cao D, Jiang Y, Zhang C, Liu Z, Zhang X, Hu X, Xu J and Du Y: Recombinant rat CC16 protein inhibits LPS-induced MMP-9 expression via NF-kappaB pathway in rat tracheal epithelial cells. Exp Biol Med 240: 1266-1278, 2015.

22. Pang M, Yuan Y, Wang D, Li T, Wang D, Shi X, Guo M, Wang C, Zhang X, Zheng G, et al: Recombinant CC16 protein inhibits the production of pro-inflammatory cytokines via NF-kappaB and p38 MAPK pathways in LPS-activated RAW264.7 macrophages. Acta biochimica et biophysica Sinica: $1-9,2017$.

23. Bayne K: Revised Guide for the Care and Use of Laboratory Animals available. American Physiological Society. Physiologist 39: 199, 208-111, 1996.

24. Ma R, Gong X, Jiang H, Lin C, Chen Y, Xu X, Zhang C, Wang J, $\mathrm{Lu} \mathrm{W}$ and Zhong N: Reduced nuclear translocation of serum response factor is associated with skeletal muscle atrophy in a cigarette smoke-induced mouse model of COPD. Int J Chron Obstruct Pulmon Dis 12: 581-587, 2017.

25. Wolfson MR, Funanage VL, Kirwin SM, Pilon AL, Shashikant BN, Miller TL and Shaffer TH: Recombinant human Clara cell secretory protein treatment increases lung mRNA expression of surfactant proteins and vascular endothelial growth factor in a premature lamb model of respiratory distress syndrome. Am J Perinatol 25: 637-645, 2008.

26. Levine CR, Gewolb IH, Allen K, Welch RW, Melby JM, Pollack S, Shaffer T, Pilon AL and Davis JM: The safety, pharmacokinetics and anti-inflammatory effects of intratracheal recombinant human Clara cell protein in premature infants with respiratory distress syndrome. Pediatr Res 58: 15-21, 2005.

27. Chilkoti A, Tan PH and Stayton PS: Site-directed mutagenesis studies of the high-affinity streptavidin-biotin complex: Contributions of tryptophan residues 79, 108 and 120. Proc Natl Acad Sci USA 92: 1754-1758, 1995.

28. Livak KJ and Schmittgen TD: Analysis of relative gene expression data using real-time quantitative PCR and the $2^{-\Delta \Delta C_{\mathrm{T}}}$ method. Methods 25: 402-408, 2001.

29. Yan C, Wang H, Aggarwal B and Boyd DD: A novel homologous recombination system to study $92 \mathrm{kDa}$ type IV collagenase transcription demonstrates that the NF-kappaB motif drives the transition from a repressed to an activated state of gene expression. FASEB J 18: 540-541, 2004.

30. Laucho-Contreras ME, Polverino F, Tesfaigzi Y, Pilon A, Celli BR and Owen CA: Club cell protein 16 (CC16) augmentation: A potential disease-modifying approach for chronic obstructive pulmonary disease (COPD). Expert Opin Ther Targets 20: 869-883, 2016.

31. Nicholas A, Jeon H, Selasi GN, Na SH, Kwon HI, Kim YJ, Choi CW, Kim SI and Lee JC: Clostridium difficile-derived membrane vesicles induce the expression of pro-inflammatory cytokine genes and cytotoxicity in colonic epithelial cells in vitro. Microb Pathog 107: 6-11, 2017. 
32. Nishino R, Fukuyama T, Watanabe Y, Kurosawa Y, Kosaka T and Harada T: Significant upregulation of cytokine secretion from T helper type 9 and 17 cells in a NC/Nga mouse model of ambient chemical exposure-induced respiratory allergy. J Pharmacol Toxicol Methods 80: 35-42, 2016.

33. Shen LL, Liu YN, Shen HJ, Wen C, Jia YL, Dong XW, Jin F, Chen XP, Sun Y and Xie QM: Inhalation of glycopyrronium inhibits cigarette smoke-induced acute lung inflammation in a murine model of COPD. Int Immunopharmacol 18: 358-364, 2014.

34. Irander K, Palm JP, Borres MP and Ghafouri B: Clara cell protein in nasal lavage fluid and nasal nitric oxide-biomarkers with anti-inflammatory properties in allergic rhinitis. Clin $\mathrm{Mol}$ Allergy 10: 4, 2012.

35. Bernard A, Marchandise FX, Depelchin S, Lauwerys R and Sibille Y: Clara cell protein in serum and bronchoalveolar lavage. Eur Respir J 5: 1231-1238, 1992.

36. Lomas DA, Silverman EK, Edwards LD, Locantore NW, Miller BE, Horstman DH and Tal-Singer R; Evaluation of COPD Longitudinally to Identify Predictive Surrogate Endpoints study investigators: Serum surfactant protein D is steroid sensitive and associated with exacerbations of COPD. Eur Respir J 34: 95-102, 2009.

37. Pilette C, Godding V, Kiss R, Delos M, Verbeken E, Decaestecker C, De Paepe K, Vaerman JP, Decramer M and Sibille Y: Reduced epithelial expression of secretory component in small airways correlates with airflow obstruction in chronic obstructive pulmonary disease. Am J Respir Crit Care Med 163 185-194, 2001

38. Laucho-Contreras ME, Polverino F, Gupta K, Taylor KL, Kelly E, Pinto-Plata V, Divo M, Ashfaq N, Petersen H, Stripp B, et al: Protective role for club cell secretory protein-16 (CC16) in the development of COPD. Eur Respir J 45: 1544-1556, 2015.

39. Chen J, Lam S, Pilon A, McWilliams A, Macaulay C and Szabo E: Higher levels of the anti-inflammatory protein $\mathrm{CC} 10$ are associated with improvement in bronchial dysplasia and sputum cytometric assessment in individuals at high risk for lung cancer. Clin Cancer Res 14: 1590-1597, 2008.

40. Zhu L, DiPY, Wu R, Pinkerton KE and Chen Y: Repression of CC16 by cigarette smoke (CS) exposure. PLoS One 10: e0116159, 2015.

41. Miller TL, Shashikant BN, Melby JM, Pilon AL, Shaffer TH and Wolfson MR: Recombinant human Clara cell secretory protein in acute lung injury of the rabbit: effect of route of administration. Pediatr Crit Care Med 6: 698-706, 2005.
42. Ma H, Wang H, Luo Y, Guo S and Song C: Mir-20b-induced increase in myeloid-derived suppressor cells in the lungs of mice with chronic asthma. Ann Clin Lab Sci 47: 76-82, 2017.

43. Reno FE, Normand P, McInally K, Silo S, Stotland P, Triest M, Carballo D and Piché C: A novel nasal powder formulation of glucagon: Toxicology studies in animal models. BMC Pharmacol Toxicol 16: 29, 2015.

44. Drost EM and MacNee W: Potential role of IL-8, platelet-activating factor and TNF-alpha in the sequestration of neutrophils in the lung: Effects on neutrophil deformability, adhesion receptor expression and chemotaxis. Eur J Immunol 32: 393-403, 2002.

45. Gibson PG, Simpson JL and Saltos N: Heterogeneity of airway inflammation in persistent asthma: Evidence of neutrophilic inflammation and increased sputum interleukin-8. Chest 119: 1329-1336, 2001.

46. Kaku Y, Imaoka H, Morimatsu Y, Komohara Y, Ohnishi K, Oda H, Takenaka S, Matsuoka M, Kawayama T, Takeya M, et al: Overexpression of CD163, CD204 and CD206 on alveolar macrophages in the lungs of patients with severe chronic obstructive pulmonary disease. PLoS One 9: e87400, 2014.

47. Shapiro SD: The macrophage in chronic obstructive pulmonary disease. Am J Respir Crit Care Med 160: S29-S32, 1999.

48. Oeckinghaus A, Hayden MS and Ghosh S: Crosstalk in NF- $\kappa \mathrm{B}$ signaling pathways. Nat Immunol 12: 695-708, 2011.

49. Zhao L, Song Y, Pu J, Guo J, Wang Y, Chen Z, Chen T, Gu Y and Jia G: Effects of repeated Cr (VI) intratracheal instillation on club (Clara) cells and activation of nuclear factor-kappa B pathway via oxidative stress. Toxicol Lett 231: 72-81, 2014.

50. Song W, Liu G, Bosworth CA, Walker JR, Megaw GA, Lazrak A, Abraham E, Sullender WM and Matalon S: Respiratory syncytial virus inhibits lung epithelial $\mathrm{Na}^{+}$channels by up-regulating inducible nitric-oxide synthase. J Biol Chem 284: 7294-7306, 2009.

51. Baeuerle PA and Henkel T: Function and activation of NF-kappa B in the immune system. Annu Rev Immunol 12: 141-179, 1994.

52. Sahebjami H and Sathianpitayakul E: Influence of body weight on the severity of dyspnea in chronic obstructive pulmonary disease. Am J Respir Crit Care Med 161: 886-890, 2000.

(i) $\odot$ This work is licensed under a Creative Commons

Attribution-NonCommercial-NoDerivatives 4.0 International (CC BY-NC-ND 4.0) License. 